\title{
A portable miniature UV-LED based photoelectrochemical system for determination of chemical oxygen demand in wastewater
}

\author{
Shanqing Zhang*, Lihong Li, Huijun Zhao, Guiying Li \\ Australian Rivers Institute \\ and \\ Griffith School of Environment \\ Gold Coast Campus, Griffith University \\ QLD 4222, Australia
}

*To whom Correspondence should be addressed:

Telephone: +61-7-5552 8155

Fax: $\quad+61-7-55528067$

Email: $\quad$ s.zhang@griffith.edu.au 
ABSTRACT

A portable, cost-effective, environmental friendly and miniature thin-layer photoelectrochemical system in conjunction with an ultraviolet light emitting diode (UV-LED) is developed for determination of chemical oxygen demand (COD), namely UV-LED PeCOD.

The COD value is directly quantified by measuring the amount of electrons captured at a nanostructured $\mathrm{TiO}_{2}$ electrode during the exhaustive photoelectrocatalytic degradation of organic species in the thin-layer cell. The key parameters of the photoelectrochemical system, such as applied potential bias, light intensity and solution $\mathrm{pH}$, were investigated and optimized. Combined with a microelectrochemical system and a laptop computer, the UV-LED PeCOD system enables end-users to perform on-site COD analysis in a simple, rapid, sensitive and accurate manner. Under the optimal conditions, the system can achieve a practical detection limit of $0.2 \mathrm{ppm}$ COD with a linear range of 0-300 ppm COD. The proposed UV-LED PeCOD technology can potentially make a revolutionary improvement to the conventional COD analysis and may be widely used in water quality monitoring industry.

Keywords: UV-LED, Chemical oxygen demand, Thin-layer cell, Photoelectrochemical, $\mathrm{TiO}_{2}$ 


\section{INTRODUCTION}

Serious global fresh water shortage problems force us to use alternative water sources, such as storm water and recycled water. This is leading to more and more rigorous environmental protection legislation being introduced to monitor and safeguard the quality of our water supply. In this regard, an advanced portable field-based analytical system can play an important role in reinforcing the implementation of this legislation.

Determination of chemical oxygen demand (COD) in waters and wastewaters is crucial for water quality assessment and pollution control as it can be used to collectively represent the organic pollution level. Standard dichromate method is often used to measure COD [1]. It is a preferred method to biochemical oxygen demand (BOD) for assessing the oxygen demand of organic pollutants in heavily polluted water bodies. This is because it needs less analysis time than the standard BOD method (i.e., 5 days) and it is immune from organic and inorganic poisons. However, this method has several drawbacks. The method involves a time-consuming degradation process $(2-4 \mathrm{~h})$ in highly acidic medium under high temperature and high pressure to allow complete oxidation of the organic material. It also requires expensive (e.g. $\mathrm{Ag}_{2} \mathrm{SO}_{4}$ ), corrosive (e.g. concentrated $\mathrm{H}_{2} \mathrm{SO}_{4}$ ) and highly toxic reagents (e.g. $\mathrm{Hg}(\mathrm{II})$ and $\mathrm{Cr}(\mathrm{VI})$ ). The latter is of particular environmental concern because of the secondary pollution. The inherent problems of long analysis time and high demanding experimental conditions make the method unsuitable for rapid and onsite monitoring of COD.

Electrocatalytic determination of $\mathrm{COD}$ using $\mathrm{PbO}_{2}$ [2-4], $\mathrm{Pt} / \mathrm{PbO}_{2}$ [5], $\mathrm{CuO}$ electrode [6], graphite-polystyrene composite electrode [7] were proposed to satisfy this demand. Although these methods have demonstrated many advantages over the traditional COD methods, such as their rapidity, simplicity and low cost, the reliability of these new methods is often not satisfactory for practical applications. This is mainly due to the fact that these methods are 
incapable of oxidizing a wide spectrum of organic compounds indiscriminately in a short period of time. This is due to the limited oxidation power of the electrochemical method.

$\mathrm{TiO}_{2}$ photocatalytic oxidation approach was also used to determine COD in water samples [8-11]. This method utilized $\mathrm{TiO}_{2}$ nanoparticles as a photocatalyst to oxidize organic compounds under UV illumination, replacing the chemical oxidants in the standard method, such as dichromate. In this process, oxygen molecules act as electron acceptors to remove electrons produced during the photocatalytic oxidation reaction. The depletion of $\mathrm{O}_{2}$ concentration in water is correlated with standard COD methods. Because the low solubility of oxygen in water $\left(<10 \mathrm{ppm}\right.$ at $\left.25^{\circ} \mathrm{C}\right)$ limits the $\mathrm{TiO}_{2}$ photocatalytic oxidation reaction, this approach suffers from the low fraction of degradation, unsatisfactory reproducibility, insufficient sensitivity, and limited dynamic working range.

The problems associated with low $\mathrm{O}_{2}$ concentration in water in the $\mathrm{TiO}_{2}$ photocatalytic oxidation process can overcome effectively by electrochemical means. A photoelectrochemical system for the determination of chemical oxygen demand, (PeCOD), was developed based on this $\mathrm{TiO}_{2}$ photocatalytic oxidation process [12-16]. Under UV illumination in a thin layer cell, organic compounds can be stoichiometrically mineralized at a $\mathrm{TiO}_{2}$ nanostructured electrode. This process can be represented as:

$\mathrm{C}_{y} \mathrm{H}_{m} \mathrm{O}_{j} \mathrm{~N}_{k} \mathrm{X}_{q}+(2 y-j) \mathrm{H}_{2} \mathrm{O} \rightarrow y \mathrm{CO}_{2}+q X^{+}+k \mathrm{NH}_{3}+(4 y-2 j+m-3 k) H^{+}+(4 y-2 j+m-3 k-q) e^{-}$

where $\mathrm{N}$ and $\mathrm{X}$ represent nitrogen and halogen atoms, respectively. The number of carbon, hydrogen, oxygen, nitrogen and halogen atoms in the organic compound is represented by $y, m$, $j, k$ and $q$, respectively.

The total amount of electrons transferred $\left(Q_{n e t}\right)$ at a $\mathrm{TiO}_{2}$ nanoporous thin-film electrode can be monitored and measured during the degradation process. According to the definition of COD 
and Faraday's Law, the measured $Q_{\text {net }}$ value is converted into an equivalent $\mathrm{O}_{2}$ concentration (or oxygen demand) $[12,13]$. The equivalent COD value can therefore be represented as:

$$
C O D(p p m)=\frac{Q_{\text {net }}}{F V} \times 8000
$$

This means that the COD value of a sample can be readily obtained by simply measuring the net charge. The method is an absolute method and requires no calibration. Other advantageous features include simplicity, rapidity, sensitivity, accuracy, limited reagent consumption (supporting electrolyte only) and no secondary pollution.

In practice, however, the previous reported system has very poor portability because the system employs a 150W xenon light source and a commercial potentiostat (PAR 363). The apparatus is large, heavy and consumes significant amounts of electricity. Besides this, the application of xenon light into the sensing application introduces several practical drawbacks, such as high cost (both the xenon lamp and the high voltage ignition electrical power source are very expensive), short life time (only a few thousand hours), high running cost, and the requirement of excellent ventilation and a dry environment. High humidity in an outdoor environment may destroy the system. These characteristics are not ideal for a portable field-based monitoring device. In order to convert the PeCOD technology into a truly portable and onsite technology for COD measurement, both the Xenon light and the conventional electrochemical station need to be replaced. The ultraviolet light emitting diode (UV-LED) is certainly a promising candidate. After a careful screening of all commercially available UV-LEDs, a UV-LED (NCCU033 from Nichia) is chosen because of its ample light intensity and suitable wavelength $\left(250 \mathrm{~mW} / \mathrm{cm}^{2}\right.$ at $\left.365 \mathrm{~nm}\right)$.

In principle, the suitability of the UV-LED for the application in PeCOD needs to be validated, because the optical characteristics of the UV light from UV-LED and Xenon light are dramatically different from each other. Xenon light consists of continuous UV wavelength [17], 
i.e., UVA $(320 \mathrm{~nm}<\lambda<380 \mathrm{~nm}), \operatorname{UVB}(280 \mathrm{~nm}<\lambda<320 \mathrm{~nm})$ and UVC $(\lambda<280 \mathrm{~nm})$, while the chosen UV-LED light is located in the UVA zone with a wavelength range of $365 \pm 5 \mathrm{~nm}$. Though thermodynamically, the photoelectrocatalytic reaction (i.e., Equation 1) can take place under any light with a wavelength $<387 \mathrm{~nm}$, kinetically, whether reaction rate under the UV-LED light is appropriate for PeCOD application has not been investigated. It was reported that the rates of the photocatalytic oxidation of organic compounds can be significantly different under different wavelengths of light. Li Puma et. al. reported that the degradation and mineralization of 2-chlorophenol were significantly faster with $\mathrm{UV}-\mathrm{ABC}$ radiation compared to the use of UVA radiation alone [18]. R. Matthew also reported that the shorter wavelength 254 $\mathrm{nm}$ radiation is considerably more effective in promoting degradation than the radiation centred at $350 \mathrm{~nm}$ for $\mathrm{TiO}_{2}$ based photocatalytic degradation of phenols [17].

In this work, the UV-LED is incorporated into a specially designed thin-layer photoelectrochemical cell for the determination of COD, namely UV-LED PeCOD. A microelectrochemical system ( $\mu$ ECS) with a size of a common USB memory stick (i.e., 66 $\times 25 \times 8 \mathrm{~mm}$ ) was used as the electrochemical system instead of the large-size conventional electrochemical station. A laptop computer is used to power the UV-LED via a USB port. At the same time it controls the $\mu \mathrm{ECS}$ to process the data and report the result in terms of COD. To optimize the system performance, the effects of important experimental parameters, such as light intensity, applied potential, and $\mathrm{pH}$ on the analytical signal generation were also systematically investigated. The detection principle is experimentally validated with the model compounds, synthetic samples and real samples.

\section{EXPERIMENTAL}

\subsection{Chemicals and Materials}


Indium Tin Oxide (ITO) conducting glass slides ( $8 \Omega /$ square) were commercially supplied by Delta Technologies Limited. Titanium butoxide (97\%) and analytical grade potassium hydrogen phthalate (KHP), hydroquinone, sucrose, maleic acid, galactose, xylose, glycine, and $L$-ascorbic acid were purchased from Aldrich without further treatment prior to use. All other chemicals were of analytical grade and purchased from Aldrich unless otherwise stated. All solutions were prepared with high purity deionised water (Millipore Corp., $18 \mathrm{M} \Omega \mathrm{cm}$ ).

\subsection{Sample Preparation}

The real samples used in this study were collected within the state of Queensland, Australia from various industrial sites including bakeries, sugar plants, breweries, canneries and dairy production plants. All samples were filtered with $0.45 \mu \mathrm{m}$ filter paper and preserved according to the guidelines of the standard method. When necessary, the samples were diluted to a suitable concentration prior to the analysis. After dilution, the same sample was subject to the analysis by both standard COD method and the UV-LED PeCOD analyzer. To the real samples and blank for photoelectrochemical determination, $\mathrm{NaNO}_{3}$ solid equivalent to $2.0 \mathrm{M}$ was added as the supporting electrolyte.

\subsection{Preparation of $\mathrm{TiO}_{2}$ film electrodes}

The details of the electrode preparation were published in our previous work [19]. Briefly, aqueous $\mathrm{TiO}_{2}$ colloid was prepared by hydrolysis of titanium butoxide according to the method described by Nazeeruddin et. al [20]. The resultant colloidal solution contains $60 \mathrm{~g} / \mathrm{L}$ of $\mathrm{TiO}_{2}$ solid with particle sizes ranging from 8 to $10 \mathrm{~nm}$. As the electrode substrate for $\mathrm{TiO}_{2}$ thin film, The ITO slide was cut into a rectangular shape with dimensions of $15 \times 40 \mathrm{~mm}$ and pretreated to assure its cleanliness. After pretreatment, the ITO slide was dip-coated in the $\mathrm{TiO}_{2}$ colloidal solution and air-dried in a clean room. The coated electrodes were then calcined at $700^{\circ} \mathrm{C}$ in a 
muffle furnace. The thickness of $\mathrm{TiO}_{2}$ porous film $(\sim 0.5 \mu \mathrm{m})$ was measured with a surface profilometer (Alpha-step 200, Tencor Instrument).

\subsection{Apparatus and methods}

All photoelectrochemical experiments were performed at $23^{\circ} \mathrm{C}$ in a thin-layer electrochemical cell with a quartz window for illumination (see Figure 1). A thin metal plate was installed as a shutter between the UV-LED and quartz window to control the ON/OFF of the illumination. The thickness of the layer is $0.10 \mathrm{~mm}$, the exposed $\mathrm{TiO}_{2}$ electrode area for UV radiation irradiation is $0.2 \mathrm{~cm}^{2}$ and the volume of the anodic compartment is ca. $2.0 \mu \mathrm{L}$. A saturated $\mathrm{Ag} / \mathrm{AgCl}$ electrode and a platinum mesh were used as the reference and counter electrodes, respectively. In Figure 1, the distance between the reference electrode and working electrode is $3 \mathrm{~mm}$, while the distance between the reference electrode and counter electrode is $4 \mathrm{~mm}$. A microelectrochemical system ( $\mu \mathrm{ECS}$, PLAB, Changchun Institute of Applied Chemistry, China - See Figure 2) powered and controlled by a DELL laptop was used for application of potential bias, current signal recording and data processing in the PeCOD measurement. Standard COD value (dichromate method) of all the samples was measured using an EPA approved COD analyzer (NOVA 30, Merck).

\section{RESULTS AND DISCUSSION}

\subsection{Photoelectrocatalytic oxidation under UV illumination}

UV-LED has attracted more and more attention regarding $\mathrm{TiO}_{2}$ photocatalysis $[21,22]$ and sensing application [23-26] due to its low cost, simplicity, low power consumption, and long life time. However, the practical barrier for UV-LED application in effective photocatalytic oxidation was that UV-LED on the market did not have sufficient intensity $\left(<1 \mathrm{~mW} / \mathrm{cm}^{2}\right)$ with sufficiently short wavelengths $(<380 \mathrm{~nm})$. The recently developed UV-LED, by Nichia, is able to emit true UV light with sufficient light intensity, i.e., $250 \mathrm{~mW} / \mathrm{cm}^{2}$ at $365 \mathrm{~nm}$. This provides 
an ideal alternative UV light source for the PeCOD technology. Figure 1 shows that the incorporation of the UV-LED into a photoelectrochemical thin-layer cell results in a portable miniature UV-LED PeCOD detector.

In the early version of PeCOD system, a fragile and expensive UV band pass filter (UG 5) was used to block the substantial heat from Xenon light to prevent solution heating up. In strong contrast, because the UV light from the UV-LED has a narrow bandwidthwavelength width of $10 \mathrm{~nm}$ (i.e., from 360 to $370 \mathrm{~nm}$ ) with no emission of visible and infra-red light, the reaction solution heating up is no longer a problem. Besides this, as a UV light source, UV-LED has several inherent advantages over the Xenon light illumination system: 1) it is small in size $(6.8 \times 6.8 \times 2.1 \mathrm{~mm})$ and light in weight $(\mathrm{ca} .10 \mathrm{~g})$, which makes it readily able to be incorporated into a compact device (See Figure 1); 2) it operates at low voltage (4.5V) and has low power consumption $(<2 \mathrm{~W})$, it can be powered by a laptop computer via a USB port and has better stability and safety, which makes it user friendly; 3) it has a much longer lifetime (ca. 100,000h, $>20$ times of Xenon lamp) with cheaper building cost (ca. 2\% of the Xenon lamp system) and operational cost (ca. 1\% of the Xenon lamp), making it economically more viable. All these merits mean the proposed UV-LED PeCOD technology possesses tremendous commercial potential as a portable sensing instrument, as well as a lab instrument.

When a $\mathrm{TiO}_{2}$ semiconductor is irradiated using UV light with a wavelength $<387 \mathrm{~nm}$, i.e., higher energy than the $\mathrm{TiO}_{2}$ band gap $(3.1 \mathrm{eV})$, electrons are promoted from the valence band to the conduction band, leaving the positively charged photohole $\left(\mathrm{h}^{+}\right)$in the valence band. In a photoelectrocatalytic system, the photo holes are forced to the interface of $\mathrm{TiO}_{2}$ and aqueous solution, while the photoelectrons are transferred to the counter electrode via the external circuit. The photo hole is a very powerful oxidizing agent $(+3.1 \mathrm{~V})$ that can readily capture an electron from any reductive species in aqueous solution, such as organic compounds and water. 
Organic compounds are normally more favourably oxidized as shown in Equation 1, though the oxidation of water is also supported thermodynamically.

$$
2 \mathrm{H}_{2} \mathrm{O}+4 \mathrm{~h}^{+} \rightarrow \mathrm{O}_{2}+4 \mathrm{H}^{+}
$$

Figure 2 shows the determination principle of the UV-PeCOD measurement. Under a constant applied potential of $+0.30 \mathrm{~V}$ ( $\mathrm{vs} \mathrm{Ag} / \mathrm{AgCl}$ ), when the light is switched off, the residual current (so-called dark current) is approximately zero, indicating that no significant electrochemical redox reaction takes place. Upon illumination, photocurrent from the blank (i.e., $i_{\text {blank }}$, solid line) and photocurrent from the organic-containing sample (i.e., $i_{\text {total }}$, dash line) increased rapidly before decaying to a common steady current. The blank photocurrent resulted from the oxidation of water (Equation 3) while the photocurrent for the sample (dash line), resulted from the overall oxidation reaction of water (Equation 3) and organic compounds (Equation 1) [27]. The attainment of the common steady current of the blank and sample suggests that all the organic compounds had been exhaustively oxidized. This is an indication of the degradation reaction endpoint and is used as the principle for the determination of the degradation time $(t)$ in this work.

After the degradation is determined, using Eq. $4 \& 5, Q_{\text {blank }}$ and $Q_{\text {total }}$ can be obtained by integration of photocurrents, $i_{\text {blank }}$ and $i_{\text {total }}$, with time, respectively. i.e.,

$$
Q_{\text {total }}=\int i_{\text {total }} d t
$$

$$
Q_{\text {blank }}=\int i_{\text {blank }} d t
$$

The net charge, $Q_{n e t}$, originated from the oxidation of organic compounds can be obtained by subtracting $Q_{\text {blank }}$ from $Q_{\text {total }}$ (see Figure 2):

$$
Q_{\text {net }}=Q_{\text {total }}-Q_{\text {blank }}
$$


$Q_{\text {net }}$ can then be used to quantify the COD value of a sample according to Equation 2.

\subsection{Optimization of experimental conditions}

\subsubsection{Light intensity}

The UV light intensity illuminated on the thin layer reactor can be regulated from 0 to $250 \mathrm{~mW} / \mathrm{cm}^{2}$ by controlling the forward current of the UV-LED and/or by adjusting relative distance between the UV-LED and the thin layer reactor. Because the UV-LED is small in size, it can be readily inserted into the thin-layer cell. In order to keep the reactor compact in size and maintain sufficient light intensity, the UV-LED is fixed at a position only $1 \mathrm{~mm}$ away from the quartz lens (see Figure 1). The UV light intensity was therefore fully controlled by the forward current in this work.

Preliminary results indicated that $Q_{n e t}$ and $Q_{b l a n k}$ remained constant when the light intensity increased from 4 to $12 \mathrm{~mW} / \mathrm{cm}^{2}$ (see Figure 3). In other words, $Q_{\text {net }}$ and $Q_{\text {blank }}$ are independent of the light intensity in this intensity range. This is expected because $Q_{\text {net }}$ originates from the oxidation of the organic compounds while $Q_{\text {blank }}$ stems from oxidation of water in the same reaction time. In the presence of sufficient $\mathrm{TiO}_{2}$ catalyst, the increase of UV light intensity leads to more photoholes being generated and therefore fast oxidation rate can be anticipated [28]. In the UV-LED PeCOD system, light intensity is directly proportional to the oxidation reaction rate of organic compounds (see Equation 1). In other words, stronger UV light intensity normally will result in shorter exhaustive degradation reaction time. The reaction time, measured from the beginning of UV illumination to the time when photocurrent reaches steady state (see Figure 2), was found to be inversely proportional to the light intensity. For instance, the reaction time for a UV-LED PeCOD essay of a sample containing $100 \mu \mathrm{M} \mathrm{KHP}$ 
can be varied from $1.5 \mathrm{~min}$ at $3.0 \mathrm{~mW} / \mathrm{cm}^{2}$ to $0.5 \mathrm{~min}$ at $9 \mathrm{~mW} / \mathrm{cm}^{2}$. From this point of view, higher light intensity means shorter reaction time.

However, in practice, too high a light intensity, e.g., $>9.0 \mathrm{~mW} / \mathrm{cm}^{2}$, is often associated with signal stability problems that are caused either by photocorrosion of the semiconductor electrode [29] or generation of $\mathrm{O}_{2}$ bubbles from the enhanced water oxidation reaction (see Equation 3). The bubbles are detrimental to any thin-layer cell analysers, because they will change the cell volume dramatically and lead to faulty measurement. It was observed that the production of bubbles became more notable when UV light intensity was over $9.0 \mathrm{~mW} / \mathrm{cm}^{2}$. It even interrupted COD measurement frequently when the light intensity was over $12 \mathrm{~mW} / \mathrm{cm}^{2}$. Therefore, practically, the light intensity needs to be carefully controlled at a value smaller than $9.0 \mathrm{~mW} / \mathrm{cm}^{2}$. Considering the above factors, a relatively low light intensity $\left(9.0 \mathrm{~mW} / \mathrm{cm}^{2}\right)$ was chosen for subsequent experiments in this work.

\subsubsection{Applied potential bias}

Applying potential bias on the working electrode can seize photogenerated electrons from the conduction band. It serves two purposes in this photoelectrocatalytic analytical system: one is to suppress the recombination of the photo-induced holes and electrons and therefore achieve high photocatalytic oxidation efficiency [12]; the other is to quantify the extent of the photoelectrocatalytic oxidation reaction by quantifying the amount of electrons originating from the oxidation reaction and subsequently determine the amount of organic compounds in the sample, using Equation 2. The effect of applied potential bias on the $Q_{\text {net }}$ and $Q_{\text {blank }}$ was therefore investigated (see Figure 4). The electrical field applied to the working electrode is directly proportional to the applied potential. Figure 4 reveals that both $Q_{n e t}$ and $Q_{\text {blank }}$ increase when the potential bias is increased from $-0.3 \mathrm{~V}$ to $+0.2 \mathrm{~V}$, which suggests that the electron collection in this potential region is the limiting step in the overall photoelectrocatalytic 
oxidation process. More importantly, the obtained $Q_{n e t}$ value for $2.0 \mu \mathrm{L}$ of $100 \mu \mathrm{M}$ KHP was significantly lower than the theoretical charge (i.e., $0.58 \mathrm{mC}$, estimated using the thin-layer cell volume). This implies that the electrical field applied in this potential region was not sufficient to completely capture the electrons originating from the oxidation reaction (Equation 1). In other words, the applied potential bias needs to be further increased. With the further potential bias increase from +0.3 to $+0.8 \mathrm{~V}$, both $Q_{\text {net }}$ and $Q_{\text {blank }}$ levelled off. $Q_{\text {net }}$ was reaching $100 \%$ of the theoretical value. This indicates that all photoelectrons generated from the photocatalytic oxidation of organics can be quantitatively collected and counted by the microelectrochemical system. In this potential range $(+0.3$ to $+0.8 \mathrm{~V})$, the overall photoelectrocatalytic oxidation process is controlled by the interfacial oxidation reaction, but not the transport of photoelectrons within the semiconductor film. In practice, high potentials have more chance of attracting electrical and electrochemical interferences. Consequently, the potential bias of $+0.3 \mathrm{~V}$ (versus $\mathrm{Ag} / \mathrm{AgCl}$ ) was chosen for subsequent experiments.

\subsubsection{Solution pH}

The $\mathrm{TiO}_{2}$ electrode has different electrochemical characteristics at different $\mathrm{pH}$. This is because the solution $\mathrm{pH}$ affects the flat band potential of the $\mathrm{TiO}_{2}$ semiconductor and speciation of the functional groups of $\mathrm{TiO}_{2}$ semiconductors [19]. Thus, $\mathrm{pH}$ may influence the photocatalytic oxidation efficiency at the $\mathrm{TiO}_{2}$ electrode in the UV-LED PeCOD system. The effect of solution $\mathrm{pH}$ on the analytical performance was then investigated.

Figure 5 shows the effect of solution $\mathrm{pH}$ on $Q_{\text {net }}$ and $Q_{\text {blank }}$ for the detection of $100 \mu \mathrm{M}$ KHP. It is observed that ITO can be seriously damaged when the $\mathrm{pH}$ is below 2 , which is evidenced by the conductivity loss of the ITO glass. Even when the solution $\mathrm{pH}$ was between 2 and $4, \mathrm{TiO}_{2}$ and ITO are still not chemically stable enough for reproducible measurements. This might explain why the measurement of $Q_{n e t}$ and $Q_{\text {blank }}$ involved dramatic fluctuation in this $\mathrm{pH}$ range. Additionally, the $Q_{\text {net }}$ value obtained was lower than the theoretical charge value (i.e., 0.58 
$\mathrm{mC}$ ), which suggests that the measurement of COD with the UV-LED PeCOD cell should not be conducted in this $\mathrm{pH}$ range. Within the $\mathrm{pH}$ range of $4.0-10.0$, both $Q_{\text {net }}$ and $Q_{\text {blank }}$ were independent of $\mathrm{pH}$ variations and, most importantly, $Q_{\text {net }}$ values obtained were very close to the theoretical charge value. When the $\mathrm{pH}$ was above 10 , a sharp increase in $Q_{\text {blank }}$ and a following sharp decrease in $Q_{n e t}$ was observed, suggesting the photocatalytic oxidation is more favourable towards water [30]. The substantial deviation from the theoretical value implies that it is not appropriate to determine COD with the UV-LED PeCOD cell in such a $\mathrm{pH}$ range. To summarise the investigation of $\mathrm{pH}$ effect, the suitable $\mathrm{pH}$ range for this proposed analytical application is between 4 and 10 . The $\mathrm{pH}$ of a sample needs to be regulated if its $\mathrm{pH}$ falls outside of this $\mathrm{pH}$ range.

\subsection{Analytical performance in analyzing synthetic samples}

The theoretical applicability of the UV-LED PeCOD method was first examined using different varieties of pure organic compounds with known oxidation numbers ( $n$ ) and theoretical COD values, including hydroquinone $(n=23)$, sucrose $(n=48)$, KHP $(n=30)$, maleic acid $(n=12)$, galactose $(n=24)$, xylose $(n=20)$, glycine $(n=6), L$-ascorbic acid $(n=20)$ and the mixture of these compounds with equal COD concentration. Figure 6 shows a group of typical photocurrent profiles for the analysis of $2.88 \mathrm{ppm}$ to $96 \mathrm{ppm}$ COD KHP while the insert within is the calibration curve of the responses. From low to high COD concentration of KHP, achievement of common well-defined steady state currents designates the reaction endpoint of the photocatalytic degradation of KHP. In low KHP concentration range (from 2.88 ppm to 19.2 ppm COD), the photocurrents declined monotonically after the UV illumination began. In strong contrast, the photocurrent at 24 and 48 ppm COD increased at first and then declined.

The contrast of current profiles became more remarkable at higher organic concentration. Photocurrents at higher KHP concentration (e.g., $>96$ ppm COD) declined for ca. $25 \mathrm{~s}$, increased 
for 60 s and subsequently declined until a steady state was reached, resulting in a shoulder peak-like profile. This was very likely due to accumulation, polymerization and degradation of intermediates during the oxidation of aromatic compounds present in high concentrations. KHP is an aromatic compound with a chemically stable benzene ring. During the degradation reaction, aromatic and other organic fragments and free radicals can be formed. The uprising portion of the photocurrent profiles at 24 and 48 ppm COD were due to accumulation of these fragments and radicals. For the photocurrent profile at 96 ppm COD, the initial decrease in photocurrent was possibly due to formation of polymer networks caused by the polymerization of the fragments and free radicals at the electrode surface. These polymer networks may diminish the mobility of the intermediates and reduce the access of the rest of the organic compounds to the electrode surface for the degradation reaction in the thin-layer cell. With the continuation of the degradation reaction, the photoholes tear off the polymer network and oxidize the resulting smaller and less stable intermediates, giving rise to the obvious increase in photocurrent. The subsequent photocurrent decrease and the attainment of the steady state apparently corresponded to the decline in residue organic compounds and their intermediates and completion of the degradation reaction, respectively. It is necessary to note that the proposed polymerization reaction may take place only when high concentrations of stable organic intermediates are available. Most importantly, this process does not affect the accuracy of COD measurement, since the net reaction ultimately follows Equation 1. This is evidenced by the calibration curve shown in the insert of Figure 6, where a good linearity with an $\mathrm{R}^{2}$ value of 0.9985 was obtained. The experimental slope $(0.0242 \mathrm{mC} / \mathrm{ppm}$ COD $)$ is closely correspondent to the theoretical slope $(0.0241 \mathrm{mC} / \mathrm{ppm} \mathrm{COD})$ estimated from the cell volume $(2.0 \mu \mathrm{L})$.

In Figure 7, PeCOD values are plotted against theoretical COD values of the selected organic compounds and their mixtures. The trend line of best fit has a slope of 1.0427 with $\mathrm{R}^{2}$ value of 
0.9955, which verifies the applicability of the proposed UV-LED PeCOD method. This demonstrates that the miniature UV-LED PeCOD cell can mineralize different organic compounds indiscriminately. In other words, it possessed exactly the same characteristics as the Xenon Light based PeCOD cell, where all organic compounds investigated were stoichiometrically oxidized to $\mathrm{CO}_{2}$ and water (see Equation 1).

A detection limit of $0.2 \mathrm{ppm}$ COD KHP and a linear range up to $300 \mathrm{ppm}$ COD KHP was obtained under the optimum experimental conditions. It should be noted that the practical linear range can be extended by a simple dilution with $2.0 \mathrm{M} \mathrm{NaNO}_{3}$ solution. The reproducibility is represented by a RSD of $1.55 \%$, obtained from 26 replicated injections of 48 ppm COD KHP. In the stability investigation, electrode fouling caused by organic contamination and bacteria growth was not observed during a storage period of 60 days. This was due to the well-known self-cleaning ability of $\mathrm{TiO}_{2}$. Because of the use of mixed-phase electrode [31], any adsorbing organic compounds on the $\mathrm{TiO}_{2}$ electrode after a long storage period (from days to months), can be demolished by the UV illumination and simultaneous injection of the blank (i.e., 2.0M $\mathrm{NaNO}_{3}$ ). No significant performance change for $Q_{n e t}$ was observed from injections of $48 \mathrm{ppm}$ COD KHP over a period of 60 days.

\subsection{Analytical performance in analyzing real samples}

The practical applicability of the method can be best demonstrated by comparing the results from real sample analysis. This was done using the UV-LED PeCOD detection and standard dichromate COD measurement with EPA approved protocols and instruments.

Chloride ion commonly exists in real samples and affects the measurement of COD with the standard method. The investigation of effect of chloride on the UV-LED PeCOD measurement was conducted and the results showed that the chloride interference was insignificant when chloride concentration is lower than $26.6 \mathrm{ppm}$. The COD value of such a sample can be directly determined by the UV-LED PeCOD method without compromising its accuracy and 
convenience. The chloride concentrations of the real samples can be controlled below $26.6 \mathrm{ppm}$ by appropriate dilutions with $2 \mathrm{M} \mathrm{NaNO}_{3}$ solution when the chloride concentration is greater than $26.6 \mathrm{ppm}$. The analysis accuracy can be maintained due to the high sensitivity of the UV-LED PeCOD method.

During the real sample analysis, it was observed that the colour of the samples had insignificant effect on the PeCOD measurement. This could be due to two reasons: a), the use of the thin layer cell (i.e., with a thickness of $0.1 \mathrm{~mm}$ ) results in very small light path for UV light absorption, b) the absorption of UV light becomes less considerable with the progress of the photoelectrocatalytic mineralisation process.

The $\mathrm{pH}$ of the real samples tested in this work was adjusted within the range of $\mathrm{pH} 4-10$ (within the aforementioned $\mathrm{pH}$-independent region) with diluted $\mathrm{HNO}_{3}$ or $\mathrm{NaOH}$ when the solution $\mathrm{pH}$ was outside the range. Figure 8 shows the correlation between the COD values obtained by both methods. The Pearson correlation coefficient was used as a measure of the intensity of association between the two methods. A highly significant correlation $(r=0.997, p=0.000, n=$ 24) between the two methods was obtained, indicating the two methods agreed very well. More importantly, the slope of the principal axis of the correlation ellipse of 0.989 was obtained. The almost identical slope values suggest both methods were accurately measuring the same COD value. Given a 95\% confidence interval, this slope was between 0.960 and 1.024. This implies that we can be $95 \%$ confident that the true slope lies between these two values. Consider that there are analytical errors associated with measurements performed by both methods and that these errors contribute to scatter on both axes. The strong correlation and almost unity in slope obtained demonstrate the applicability of the UV-LED thin layer photoelectrochemical cell for determination of chemical oxygen demand.

\section{Conclusion}


416 The validation experiments using pure organic compounds, artificial mixtures and real samples

417 demonstrate that the UV-LED thin-layer photoelectrochemical cell can be used to determine

418 COD in wastewaters in a rapid, sensitive and accurate fashion.

419 The UV-LED PeCOD system gathers the advantages of the modern LED technology (long life, 420 low power consumption and low cost), the microelectrochemical system, and merits of the 421 original PeCOD technology, while eradicating the drawbacks of the traditional xenon light optical system and conventional photoelectrochemical station. This makes the technology portable and more user-friendly.

The successful incorporation of UV-LED into the miniature photoelectrochemical thin-layer cell makes the commercialization of the PeCOD technology possible. The proposed UV-LED PeCOD technology will very likely make a revolutionary improvement for the conventional COD analysis and may be widely used in water quality monitoring industry.

\section{Acknowledgements} from Australian Research Council. 
[1] American Public Health Association, American Water Works Association., Water Environment Federation, Standard methods for the examination of water and wastewater, Apha-Awwa-Wef, Washington, D.C., 1995.

[2] U. Pilz, Wasser, Abwasser, Abfall 8 (1992) 525. R. Roessler-Fromme, F. Scholz, Fresenius J. Anal. Chem. 356 (1996) 197-201.

[4] S. Ai, M. Gao, Y. Yang, J. Li, L. Jin, Electroanal. 16 (2004) 404-09.

[5] P. Westbroek, E. Temmerman, Anal. Chim. Acta 437 (2001) 95-105.

[6] K.-H. Lee, T. Ishikawa, S. McNiven, Y. Nomura, S. Sasaki, Y. Arikawa, I. Karube, Anal. Chim. Acta 386 (1999) 211-20.

[7] J. Orozco, C. Fernandez-Sanchez, E. Mendoza, M. Baeza, F. Cespedes, C. Jimenez-Jorquera, Anal. Chim. Acta 611 (2008) 250.

[8] Y.C. Kim, S. Sasaki, K. Yano, K. Ikebukuro, K. Hashimoto, I. Karube, Anal. Chim. Acta 432 (2001) 59-66.

[9] Y.-C. Kim, K.-H. Lee, S. Sasaki, K. Hashimoto, K. Ikebukuro, I. Karube, Anal. Chem. 72 (2000) 3379-82.

[10] Y.-C. Kim, S. Sasaki, K. Yano, K. Ikebukuro, K. Hashimoto, I. Karube, Analyst (Cambridge, U. K.) 125 (2000) 1915-18.

[11] Y.-C. Kim, S. Sasaki, K. Yano, K. Ikebukuro, K. Hashimoto, I. Karube, Anal. Chem. 74 (2002) 3858-64.

[12] H. Zhao, D. Jiang, S. Zhang, K. Catterall, R. John, Anal. Chem. 76 (2004) 155-60.

[13] S. Zhang, H. Zhao, D. Jiang, R. John, Anal. Chim. Acta 514 (2004) 89-97.

[14] S. Zhang, D. Jiang, H. Zhao, Environ.1 Sci. \& Technol. 40 (2006) 2363-68.

[15] H. Zhao, S. Zhang, Improved water analysis, WO 2008077191, 2008.

[16] H. Zhao, S. Zhang, Improved online water analysis, WO 2008077192, 2008.

[17] R.W. Matthews, S.R. McEvoy, J. Photochem. Photobiol., A 66 (1992) 355-66.

[18] G. Li Puma, P.L. Yue, Chem. Eng. Technol. 56 (2001) 2733-44.

[19] D. Jiang, H. Zhao, S. Zhang, R. John, G.D. Will, J. Photochem. Photobiol., A 156 (2003) 201-06.

[20] M.K. Nazeeruddin, A. Kay, I. Rodicio, R. Humphry-Baker, E. Mueller, P. Liska, N. Vlachopoulos, M. Graetzel, J. Am. Chem. Soc. 115 (1993) 6382-90.

[21] D.H. Chen, X. Ye, K. Li, Chem. Eng. Technol. 28 (2005) 95-97.

[22] W.-Y. Wang, Y. Ku, Water Res. 40 (2006) 2249-58.

[23] C.-H. Han, D.-W. Hong, S.-D. Han, J. Gwak, K.C. Singh, Sens. Actuator, B 125 (2007) 224-28.

[24] N. Kurilcik, P. Vitta, A. Zukauskas, R. Gaska, A. Ramanavicius, A. Kausaite, S. Jursenas, Opt. Appl. 36 (2006) 193-98.

[25] M. Turel, M. Cajlakovic, E. Austin, J.P. Dakin, G. Uray, A. Lobnik, Sens. Actuator, B131 (2008) 247-53.

[26] D. Daniel, I.G.R. Gutz, Electrochem. Commun. 9 (2007) 522-28.

[27] S.N. Frank, A.J. Bard, J. Am. Chem. Soc. 99 (1977) 4667-75.

[28] D. Jiang, H. Zhao, S. Zhang, R. John, J. Phys.Chem. B 107 (2003) 12774-80.

[29] G.N. Brown, J.W. Birks, C.A. Koval, Anal. Chem. 64 (1992) 427-34.

[30] J. Rappich, J.K. Dohrmann, J. Phys.Chem. 93 (1989) 5261-4.

[31] D. Jiang, S. Zhang, H. Zhao, Environ. Sci. Technol. 41 (2007) 303-08. 


\section{Figure Captions}

Figure 1 Schematic diagram of the design of the UV-LED thin-layer photoelectrochemical cell.

Figure 2 Typical photocurrent responses of a blank solution containing $2.0 \mathrm{M} \mathrm{NaNO}_{3}$ (solid line) and a sample containing organic compounds and $2.0 \mathrm{M} \mathrm{NaNO}_{3}$ solution (dash line). The shaded area indicates the charge originated from the complete oxidation of organic compounds in the thin-layer cell. The insert shows the images and dimensions of the UV-LED and $\mu$ ECS system.

Figure 3 Effect of light intensity on $Q_{\text {net }}$ and $Q_{\text {blank }}$ for the photoelectrochemical oxidation of $100 \mu \mathrm{M} \mathrm{KHP}$ and its blank solution.

Figure 4 Effect of potential bias on $Q_{\text {net }}$ and $Q_{\text {blank }}$ for the photoelectrochemical oxidation of $100 \mu \mathrm{M} \mathrm{KHP}$ and its blank solution.

Figure 5 Effect of $\mathrm{pH}$ on $Q_{\text {net }}$ and $Q_{\text {blank }}$ for the photoelectrochemical oxidation of $100 \mu \mathrm{M}$ KHP and its blank solution.

Figure 6 Typical photocurrent responses at various KHP concentrations: from bottom to the top: 0 (blank), 2.88, 4.8, 9.6, 14.4, 19.2, 2448 and 96 ppm COD KHP. The insert figure is the correlation between $Q_{\text {net }}$ and theoretical COD values.

Figure 7 The correlation between the PeCOD and the theoretical COD values of different organic compounds and synthetic samples.

Figure 8 The correlation between the PeCOD and the standard COD value of real samples. 


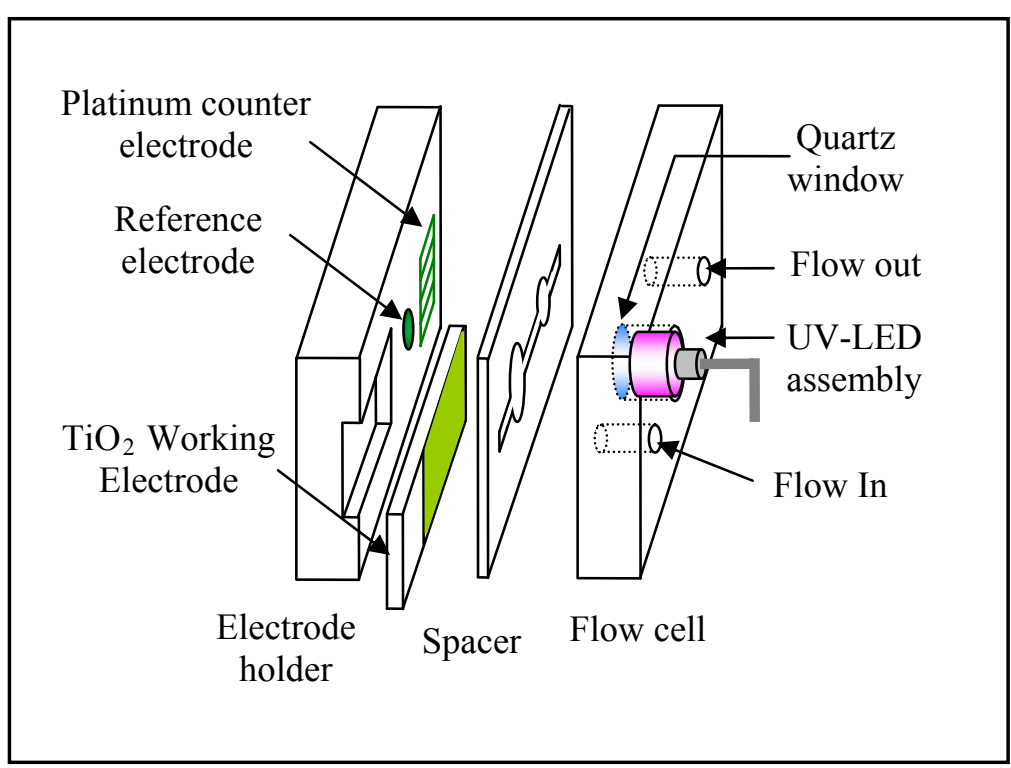

499

Figure 1.

(to be reproduced in color on the Web (free of charge) and in black-and-white in print) 


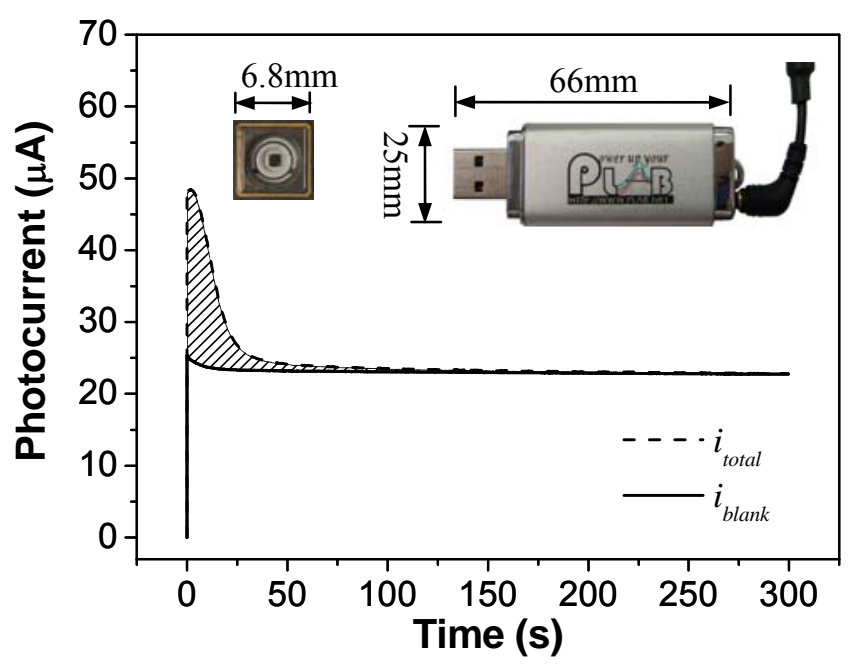

502

503 Figure 2.

504 (to be reproduced in color on the Web (free of charge) and in black-and-white in print) 


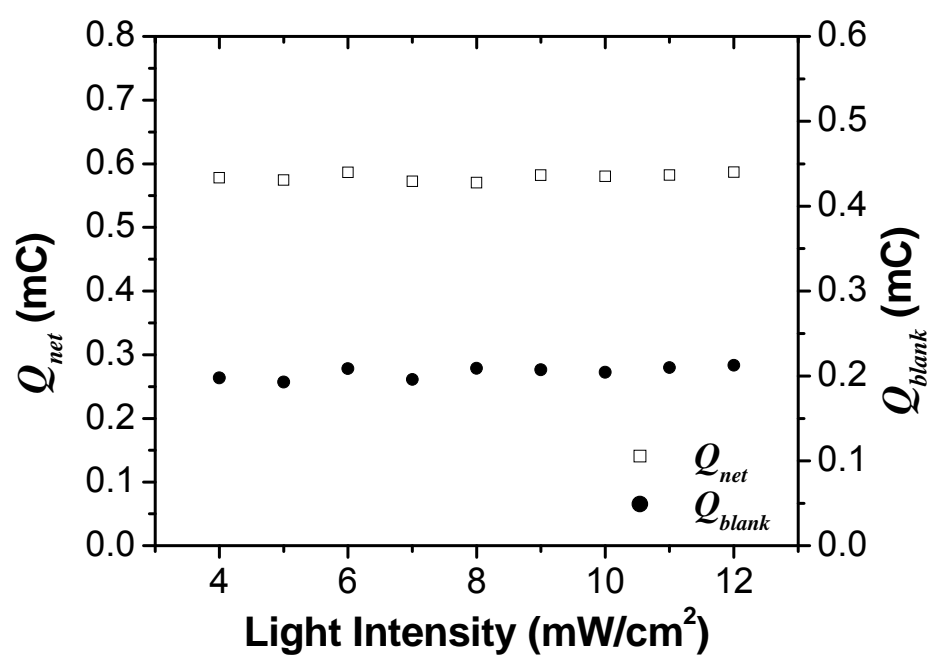

506

507 Figure 3. 


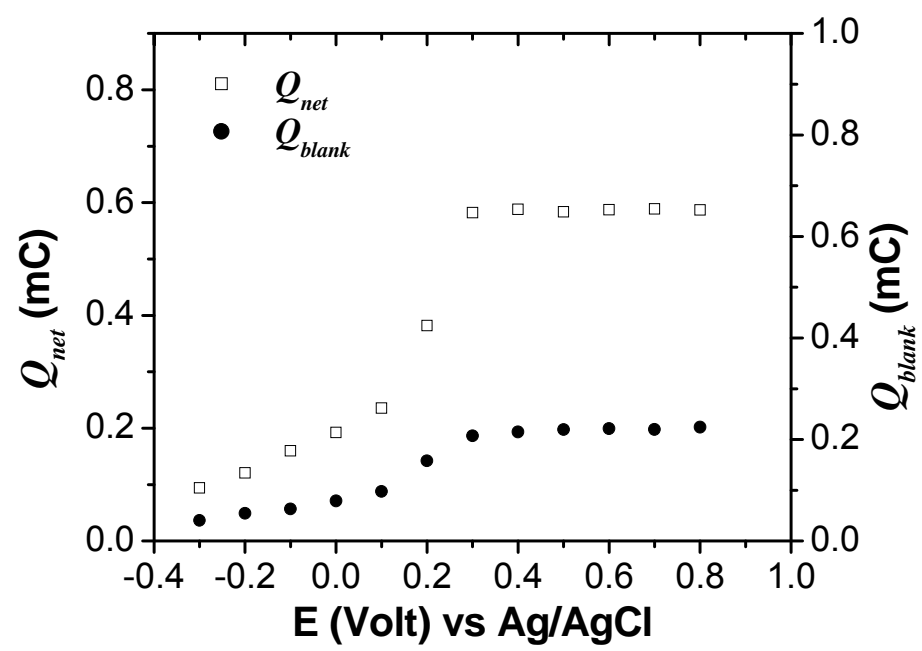

509

$510 \quad$ Figure 4. 


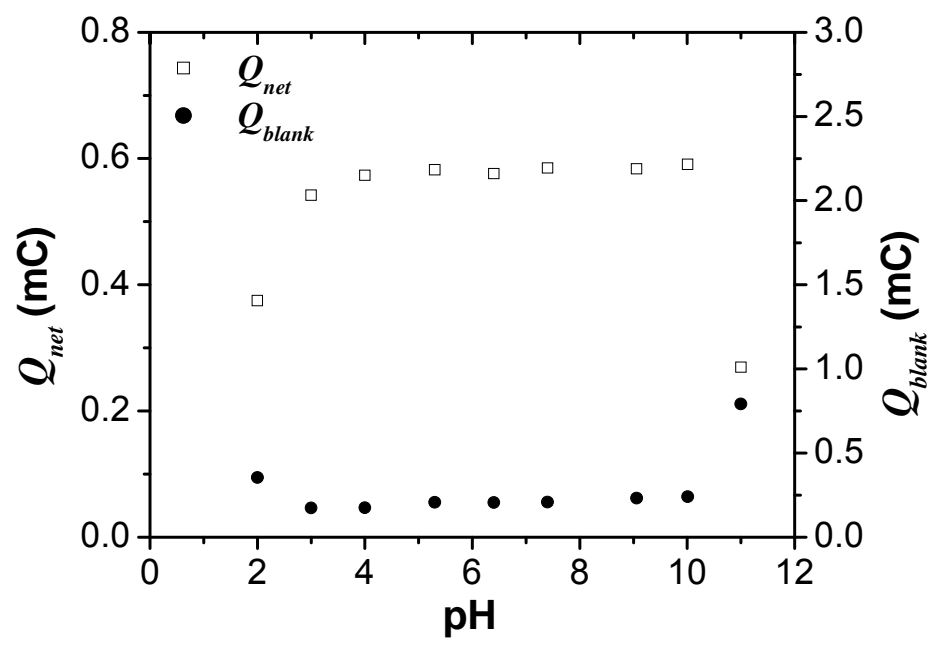

512

513 Figure 5. 


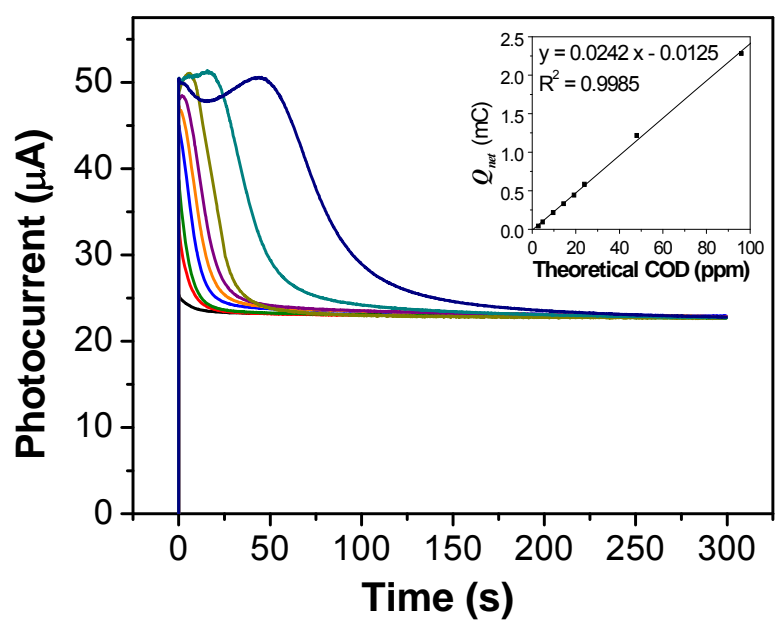

515

516 Figure 6.

517 (to be reproduced in color on the Web (free of charge) and in black-and-white in print) 


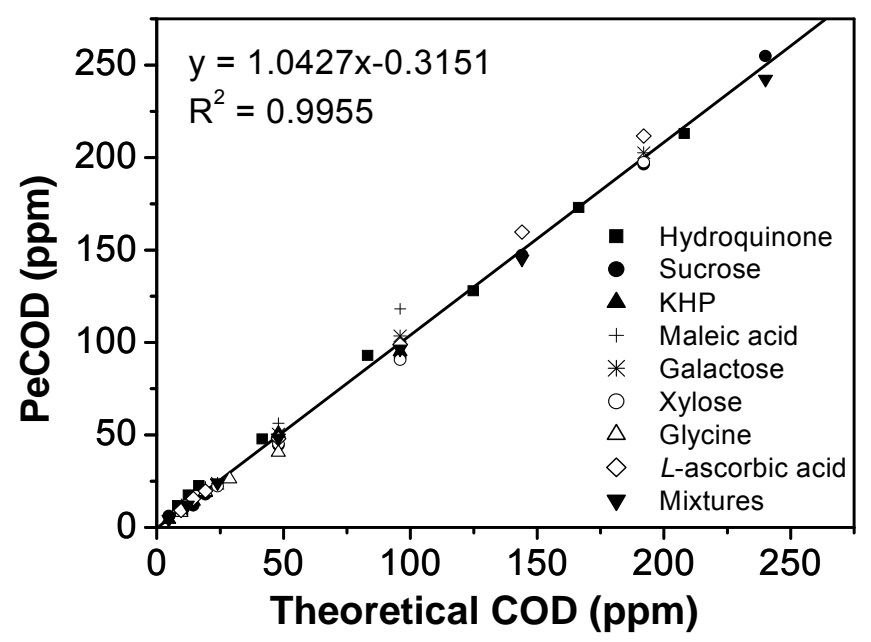

519

$520 \quad$ Figure 7. 


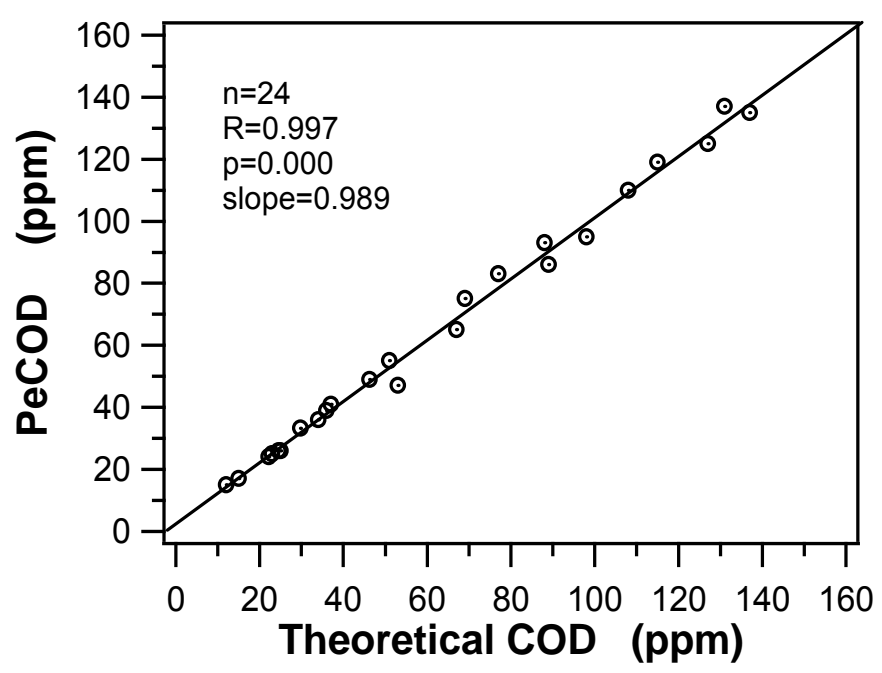

523 Figure 8. 